Journal of Epidemiology and Public Health (2018), 3(2): 292-306

https://doi.org/10.26911/jepublichealth.2018.03.02.08

\title{
Biopsychosocial Factors Affecting Functional Disability and Depression in Patients with Osteoarthritis in Surakarta, Central Java
}

\author{
Wahyu Tri Sudaryanto'), Ambar Mudigdo'), RB Soemanto') \\ ${ }^{1)}$ Masters Program in Public Health, Universitas Sebelas Maret \\ 2)Faculty of Medicine, Universitas Sebelas Maret \\ 3)Faculty of Social and Political Sciences, Universitas Sebelas Maret
}

\begin{abstract}
Background: Osteoarthritis (OA) is a major cause of disability in the elderly. OA can cause chronic pain, disability, and the patient's quality of life. This study aimed to determine the biopsychosocial factors affecting functional disability and depression in patients with OA in Surakarta, Central Java.

Subjects and Method: This was an analytic and observational study with a case-control design. The study was conducted at Dr. Moewardi Hospital and Dr. Soeharso Orthopedic Hospital, Surakarta, Central Java, from January to February 2018. A sample of 200 OA patients was selected by simple random sampling. The dependent variables were functional disability and depression. The independent variables were age, sex, grade of OA, duration, body mass index (BMI), history of injury, pain level, family support, and peer support. Depression data were measured by Beck's Depression Inventory (BDI). Functional disability data were measured by The Western Ontario and McMaster University Arthritis Index (WOMAC). The other variables were collected by questionnaire. The data were analyzed by path analysis.

Results: The risk of depression increased with higher BMI $(b=0.23 ; \mathrm{SE}=0.10 ; \mathrm{p}=0.021)$, pain level $(b=0.16 ; \mathrm{SE}=0.07 ; \mathrm{p}=0.022)$, duration (year) $(\mathrm{b}=0.27 ; \mathrm{SE}=0.12 ; \mathrm{p}=0.025)$, and poor functional disability $(\mathrm{b}=0.19 ; \mathrm{SE}=0.04 ; \mathrm{p}<0.001)$. Depression decreased with stronger family support $(b=-0.05 ; \mathrm{SE}=0.03 ; \mathrm{p}=0.031)$ and stronger peer support $(\mathrm{b}=-0.09 ; \mathrm{SE}=0.05 ; \mathrm{p}=0.001)$. The risk of functional disability increased with female sex $(b=3.36 ; \mathrm{SE}=1.21 ; \mathrm{p}=0.006)$, age $(b=$ $0.14 ; \mathrm{SE}=0.06 ; \mathrm{p}=0.016)$, $\mathrm{BMI}(\mathrm{b}=0.31 ; \mathrm{SE}=0.17 ; \mathrm{p}=0.070)$, had experienced injury $(\mathrm{b}=2.27$; $\mathrm{SE}=1.16 ; \mathrm{p}=0.051)$, higher grade of $\mathrm{OA}(\mathrm{b}=1.32 ; \mathrm{SE}=0.65 ; \mathrm{p}=0.041)$, and higher pain level $(\mathrm{b}=$ $0.41 ; \mathrm{SE}=0.12 ; \mathrm{p}<0.001)$. The risk of functional disability decreased with stronger family support $(b=-0.16 ; \mathrm{SE}=0.04 ; \mathrm{p}<0.001)$ and stronger peer support $(\mathrm{b}=-0.29 ; \mathrm{SE}=0.08 ; \mathrm{p}<0.001)$.

Conclusion: Depression in OA patients is affected by BMI, pain level, duration (year), functional disability family support, and peer support. Functional disability is affected by sex, age, BMI, injury experience, grade of OA, pain level, family support, and peer support.
\end{abstract}

Keywords: osteoarthritis, depression, functional disability, pain, BMI, family support, peer support

\section{Correspondence:}

Wahyu Tri Sudaryanto. Masters Program in Public Health, Universitas Sebelas Maret, Jl. Ir. Sutami 36 A, Surakarta 57126, Central Java.

Email: wahyu.londho86@yahoo.co.id. Mobile: 085640637769.

\section{BACKGROUND}

Osteoarthritis (OA) is a long-term chronic disease characterized by cartilage disorder in joint that cause bone to rub against each other and create stiffness, pain, and disturbed movement. Osteoarthritis commonly affects knee, hand, feet, and hip joints (Haq et al., 2003). Osteoarthritis is a major cause of disability in the elderly (Laupattarakasem et al., 2008). 
According to Basic Health Research year 2007, osteoarthritis is a disease that often occurs with age. As many as $12.1 \%$ of Americans aged 25-75 years suffer from knee, hip, and hand osteoarthritis, while in England $25 \%$ of the population aged $\geq 55$ years suffer from knee osteoarthritis.

World Health Organization reported that people with joint disorders in Indonesia account for $81 \%$ of the elderly population. Based on that percent, as much as $24 \%$ who went to the doctor, while as much as $71 \%$ immediately consume painkillers sold drugs freely.

Osteoarthritis is commonly associated with aging, but it is also associated with non-modifiable factors, including gender, genetics, obesity, bone density, workplace accidents, trauma/injury, and poor exercise (Haq et al., 2003). Higher body mass index may increase the risk of musculoskeletal disorder and osteoarthritis (Pooye and Barbara, 2010).

Blagojevicy et al. (2010) reported that obesity, a history of trauma / injury in the knee joint, female sex, and older age were at greater risk of osteoarthritis of the knee joint. Osteoarthritis may cause disability in the elderly, reduce quality of life, and contribute to the limitations of daily physical activity. The high prevalence of osteoarthritis, chronicity, and the impact of disability is related to the economic burden on the patient and the health system (Hootman and Helmick, 2006).

According to the WHO Global Burden of Disease Study in 21 countries around the world there is an increase in knee joint osteaortritis load measured by years lived with disability (YLDs) per 100,000 of 26.6\% from 1990 to 2010 (Vos et al., 2012).

Biopsychosocial models are considered appropriate to be applied to arthritis disorders such as osteoarthritis and rheumatoid arthritis. The biopsychosocial model is seen as a useful approach to understanding pain and disability (Keefe et al., 2002).

\section{SUBJECTS AND METHOD}

\section{Study Design}

This was an analytic observational study with a cross-sectional design. The study was conducted at Dr. Moewardi Hospital and Dr. Soeharso Orthopedic Hospital, Surakarta, Central Java, from January to February 2018.

\section{Population and Sample}

Population in this study was OA patients in Surakarta, Central Java. A sample of 200 in and out secondary OA patients at Dr. Moewardi and Prof. Dr. Soeharso Orthopedic Hospital, Surakarta was selected by simple random sampling.

\section{Study Variables}

The dependent variables were functional disability and depression. The independent variables were age, sex, body mass index (BMI), grade of OA, duration of OA illness, history of injury, pain level, family support, and peer support.

\section{Operational Definition of Variables} Functional disability was defined as the study subject's limitations to perform daily functional activities considered to be due to osteoarthritis. The data were collected by The Western Ontario and McMaster University Osteoarthritis Index (WOMAC) questionnaire. The measurement scale was continuous.

Depression was defined as a state of mind or mood disorder characterized by loss of energy to perform activities, pessimism, and vegetative symptoms (such as weight loss and sleeplessness) due to osteoarthritis. The data were collected by Beck Depression Inventory (BDI) questionnaire. Measurement scale was continuous.

Age was defined as the number of years study subject has been alive from 
Journal of Epidemiology and Public Health (2018), 3(2): 292-306

https://doi.org/10.26911/jepublichealth.2018.03.02.08

birth to the data was taken. The data was collected by questionnaire. Measurement scale was continuous.

Sex was defined as a sexual distribution determined by biology and anatomy aspects and expressed in male and female. The data was collected by questionnaire. The measurement scale was categorical, transformed into dichotomous coded as follows, i.e. $\mathrm{o}$ for male and $\mathbf{1}$ for female.

Assessment of nutritional status using weight size adjusted for height, calculated by the formula: body weight $(\mathrm{kg}) /$ body height $\left(\mathrm{m}^{2}\right)$. BMI calculation was adjusted according to the BMI criteria of the Asia Pacific population. Measurement scale was continuous.

The history of injury was defined as a history of the study subjects experiencing injury, trauma, fractures in the joint region suspected of having an impact on increased risk of osteoarthritis. The data was collected by questionnaire. The measurement scale was categorical, transformed into dichotomous coded o for had not experienced injury and 1 for had experienced injury.

Chronic joint pain was defined as an unsettling sensory and emotional experience felt by the study subject due to the presence of osteoarthritis. The data was collected by Visual Analog Scale (VAS). Measurement scale was continuous.

Peer support was defined as all forms of support including informational support, emotional support, assessment support, and the instrumental support provided by peers in preventing depression. The data was collected by questionnaire. Measurement scale was continuous.

Family support was defined as all forms of support including informational support, emotional support, assessment support, and the instrumental support provided by family members in preventing depression. The data was collected by questionnaire. Measurement scale was continuous.

\section{Data Analysis}

The result of characteristic analysis of study subject and univariate analysis in the form of categorical/ dichotomy data was described in frequency (n) and percent (\%). Bivariate analysis was performed using ChiSquare test. Multivariate analysis using path analysis with SPSS Stata program, through the following steps:
a. Model specification
b. Model identification
c. Model fit
d. Estimation
e. Model respecification
6. Research ethics

The research ethics clearance was obtained from the Research Committe at Dr. Moewardi Hospital. Research ethics included informed consent, anonimity, and confidentiality.

\begin{tabular}{l}
\hline RESULTS \\
A. Characteristics of study subject \\
Table 1 showed the characteristics of the \\
study subjects. Most of the study subjects \\
were female $(77 \%), 33.5 \%$ had education \\
senior high school, and $31 \%$ was civil \\
servant. \\
Table 2 showed the characteristics of \\
OA patient. Most of OA patient (68.5\%) did \\
not have a history of injury. The most \\
common type of osteoarthritis experienced \\
by study subject in Dr. Moewardi Hospital \\
and Prof. Dr. Soeharso Orthopedic Hospital \\
was bilateral genu OA with the highest \\
grade of OA was grade 2.
\end{tabular}

\section{A. Characteristics of study subject}

Table 1 showed the characteristics of the study subjects. Most of the study subjects were female (77\%), 33.5\% had education senior high school, and $31 \%$ was civil Table 2 showed the characteristics of OA patient. Most of OA patient (68.5\%) did not have a history of injury. The most common type of osteoarthritis experienced by study subject in Dr. Moewardi Hospital and Prof. Dr. Soeharso Orthopedic Hospital grade of OA was grade 2 . 
Sudaryanto et al./ Biopsychosocial Factors Affecting Functional Disability

Table 1. Characteristics of the study subject

\begin{tabular}{llcc}
\hline \multicolumn{1}{c}{ Characteristics } & \multicolumn{1}{c}{ Category } & N & \% \\
\hline Sex & Female & 154 & 77.0 \\
Mducation & Note & 46 & 23.0 \\
& Elementary school & 13 & 6.5 \\
& Junior high school & 24 & 12.5 \\
& Senior high school & 26 & 13.5 \\
& Diploma & 67 & 33.5 \\
& Bachelor & 9 & 4.5 \\
& Post graduate & 60 & 30 \\
& Laborers & 1 & 0.5 \\
& Teacher & 8 & 4.0 \\
& Housewife & 7 & 3.5 \\
& Seller & 59 & 29.5 \\
& Employee & 12 & 6.0 \\
& Street singer & 1 & 0.5 \\
& Tailor & 1 & 0.5 \\
& Herbal drink seller & 1 & 0.5 \\
& Retired civil servant & 2 & 1.0 \\
& Retired midwife & 62 & 31.0 \\
& Retired teacher & 1 & 0.5 \\
& Bridal bracelets & 9 & 4.5 \\
& Farmer & 1 & 0.5 \\
& Civil servants & 11 & 5.5 \\
& Driver & 3 & 1.5 \\
& Private employee & 1 & 0.5 \\
& Entrepreneur & 9 & 6.0 \\
& & & 4.5 \\
\hline
\end{tabular}

Table 2. Type of OA in study subjects

\begin{tabular}{llcc}
\hline \multicolumn{1}{c}{ Characteristic } & \multicolumn{1}{c}{ Category } & N & \% \\
\hline Had experienced injury & Yes & 63 & 31.5 \\
Type of OA & No & 137 & 68.5 \\
& ankle dextra OA & 1 & 0.5 \\
& ankle sinistra OA & 1 & 0.5 \\
& ankle bilateral OA & 1 & 0.5 \\
& elbow dextra OA & 1 & 0.5 \\
& genu dextra OA & 40 & 20.0 \\
& genu sinistra OA & 39 & 19.5 \\
& genu bilateral OA & 109 & 54.5 \\
& hip dextra OA & 2 & 1.0 \\
Grade of OA & hip sinistra OA & 4 & 2.0 \\
& hip bilateral OA & 2 & 2.0 \\
& Grade 1 & 61 & 30.5 \\
& Grade 2 & 98 & 49.0 \\
& Grade 3 & 32 & 16.0 \\
& Grade 4 & 9 & 4.5 \\
\hline
\end{tabular}


Journal of Epidemiology and Public Health (2018), 3(2): 292-306

https://doi.org/10.26911/jepublichealth.2018.03.02.08

\section{B. Univariate analysis}

Table 3. The results of univariate analysis

\begin{tabular}{lcccc}
\hline \multicolumn{1}{c}{ Characteristics } & Mean & SD & Min. & Max. \\
\hline Age (year) & 66.24 & 8.59 & 37 & 86 \\
Duration (year) & 3.10 & 2.43 & 0.5 & 15 \\
Body weight (kg) & 57.53 & 8.71 & 40 & 80 \\
Body height (cm) & 155.36 & $5 \cdot 71$ & 140 & 174 \\
BMI & 23.79 & 3.07 & 17.07 & 30.18 \\
Income (Rupiah) & $1,966,950$ & $1,012,534.11$ & 500, ooo & 5,000, o00 \\
Pain level & 9.95 & 4.79 & 2 & 24 \\
Depression & 10.08 & 5.26 & 2 & 26 \\
Functional disability & 27.55 & 9.06 & 9 & 52 \\
Family support & 26.62 & 12.50 & 3 & 56 \\
Peer support & 10.36 & 6.75 & 0 & 31 \\
\hline
\end{tabular}

\section{Bivariate analysis}

The results of bivariate analysis of biopsychosocial factors affecting functional disability in OA patient using Pearson product-moment were shown in Table 4. The result of the bivariate analysis showed that age, female gender, grade of $\mathrm{OA}$, duration of OA illness, BMI, history of injury, and pain level increased the risk of functional disability in OA patient. Family support and peer support reduced the risk of functional disability.

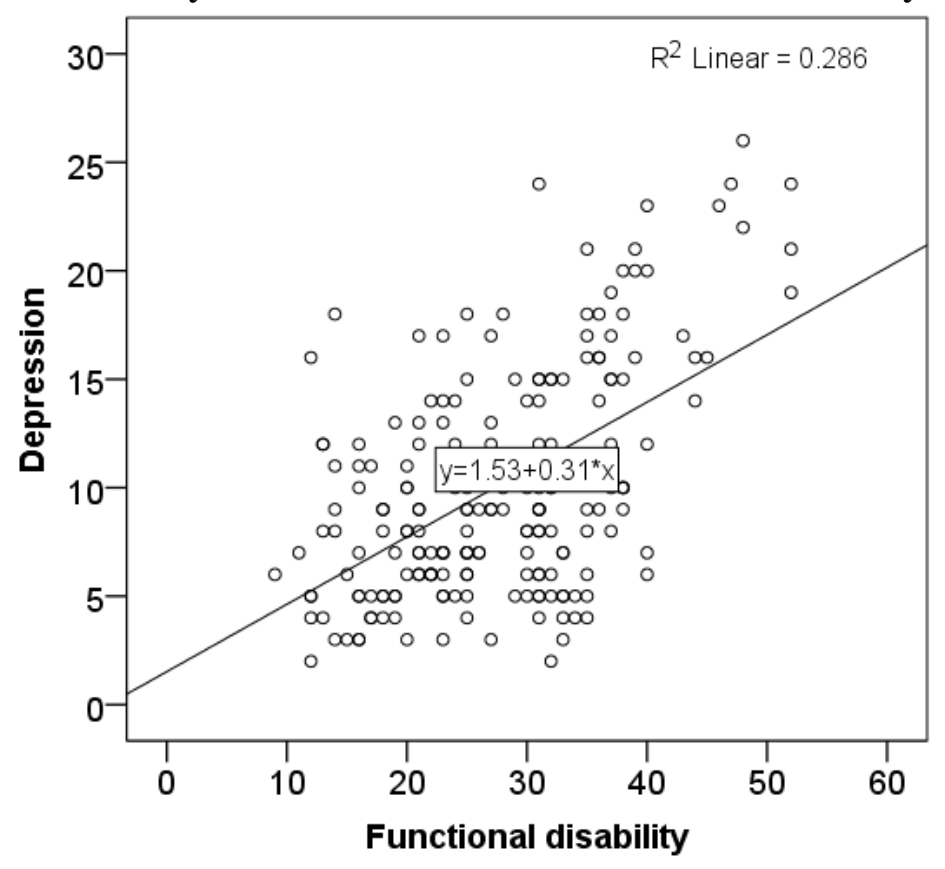

\section{Figure 1. Scatter plot on the relationship between participation in peer support group and functional dysability}

Figure 1 shows scatter plot on the relationship between functional disability and depression in OA patients. It shows positive relationship between functional disability and depression. 
Table 4. The analysis of biopsychosocial factors affecting functional disability in oA patient using Pearson product moment test

\begin{tabular}{lcc}
\hline \multicolumn{1}{c}{ Variabel independen } & $\mathbf{r}$ & $\mathbf{p}$ \\
\hline Age (year) & 0.06 & 0.437 \\
Sex & 0.30 & $<0.001$ \\
Grade of OA & 0.27 & $<0.001$ \\
Duration of OA illness (year) & 0.07 & 0.294 \\
Education level & 0.08 & 0.236 \\
Employment status & 0.03 & 0.667 \\
BMI & 0.26 & $<0.001$ \\
Income (Rupiah) & -0.12 & 0.081 \\
History of injury & 0.33 & $<0.001$ \\
Pain level & 0.46 & $<0.001$ \\
Family support & -0.37 & $<0.001$ \\
Peer support & -0.34 & $<0.001$ \\
\hline
\end{tabular}

The results of bivariate analysis of biopsychosocial factors affecting depression in OA patients using Pearson productmoment are shown in Table 5 . The results of the bivariate analysis showed that age, female gender, grade of OA, duration of OA illness, education, occupation, BMI, history of injury, pain level, and functional disability increased the risk of depression in OA patient. Family income, family support, and peer support decreased the risk of depression

Table 5. The analysis of factors affecting functional disability and depression in patients with osteoarthritis using Pearson product moment

\begin{tabular}{lcc}
\hline \multicolumn{1}{c}{ Independent variables } & $\mathbf{r}$ & $\mathbf{p}$ \\
\hline Age (year) & 0.05 & 0.528 \\
Sex & 0.19 & 0.009 \\
Grade of OA & 0.20 & 0.004 \\
Duration of OA illness (year) & 0.16 & 0.021 \\
Education level & 0.05 & 0.452 \\
Employment status & 0.08 & 0.280 \\
BMI & 0.28 & $<0.001$ \\
Income (Rupiah) & -0.02 & 0.760 \\
History of injury & 0.33 & $<0.001$ \\
Pain level & 0.40 & $<0.001$ \\
Functional disability & 0.54 & $<0.001$ \\
Family support & -0.34 & $<0.001$ \\
Peer support & -0.30 & $<0.001$ \\
\hline
\end{tabular}

\section{D.Path analysis}

\section{Model identification}

a. Observed variable $=11$

Endogenous variable $=3$

Exogenous variable $=8$

Number of parameter $=58$ follows:
Degree of freedom formula, as $\mathrm{df}=$ (observed variable $\mathrm{x}$ (observed variable +1$)) / 2-($ endogenous variable + exogenous variable+ parameter)

$$
=(11 \times(11+1)) / 2-(3+8+47)
$$$$
=66-58=8
$$

Degree of freedom value $>1$ indicated that path analysis can be done. Figure 1 showed the structural model after estimation using SPSS Amos program. 
Journal of Epidemiology and Public Health (2018), 3(2): 292-306

https://doi.org/10.26911/jepublichealth.2018.03.02.08

Fit model indicators including:

1) Normed Chi Square $(\mathrm{CMIN})=10.16$ with $\mathrm{p}=0.254(>0.05)$;

2) Goodness of Fit Index (GFI) $=0.99$ $(\geq 0.90)$;
3) Normed Fit Index (NFI) $=0.97(\geq 0.90)$;

4) Comparative Fit Index (CFI) $=0.99$ $(\geq 0.90)$;

5) Root Mean Square Error of Approximation $($ RSMEA $)=0.04(<0.08)$.

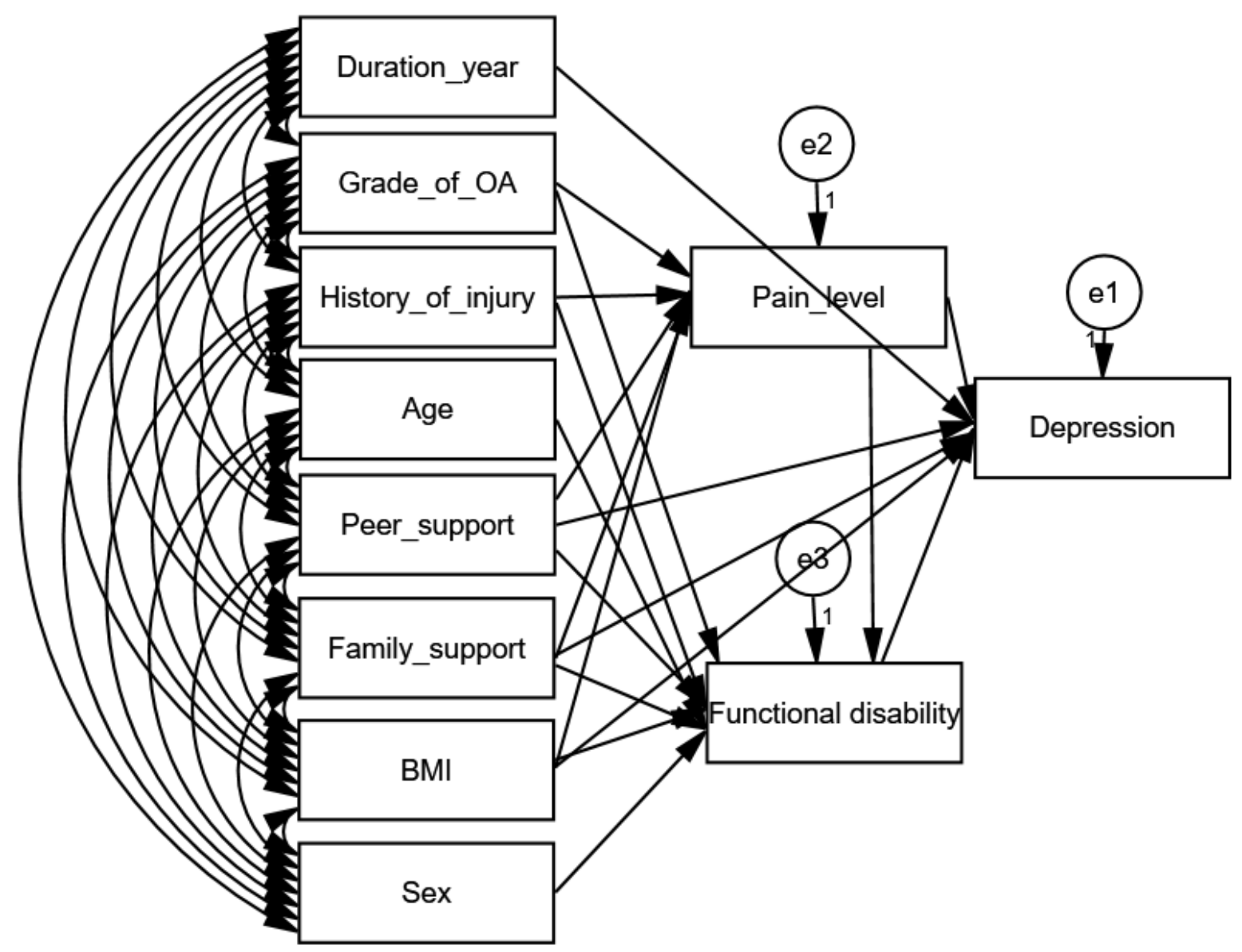

Figure 1. Fit model and parameter estimation of path analysis

These values indicate that path analysis model in Figure 1 meets the criteria specified and expressed in accordance with the empirical data.

1) Factors directly affecting to depression in OA patient

Depression in OA patient was directly affected by BMI, pain level, duration, functional disability, family support, and peer support.

a) BMI was positively affected to depression in OA patient. Higher depression increased with higher BMI $(b=0.23$; $\mathrm{SE}=0.10 ; \mathrm{p}=0.021$. b) Pain level was positively affected to depression in OA patient. Negative perception in pain increased depression $(\mathrm{b}=$ $0.16 ; \mathrm{SE}=0.07 ; \mathrm{p}=0.022$ ).

c) Duration (year) was positively affected to depression in OA patient. The longer the OA patients suffering from OA had an effect on increasing depression $(b=0.27$; $\mathrm{SE}=0.12 ; \mathrm{p}=0.025$ ).

d) Functional disability was positively affected to depression in OA patient. Higher functional disability increased depression $(\mathrm{b}=0.19 ; \mathrm{SE}=0.04 ; \mathrm{p}$ $<0.001)$. 
e) Family support was negatively affected to depression. Strong family support decreased depression $(b=-0.05 ; \mathrm{SE}=$

o.03; $\mathrm{p}=0.031$ ).

Table 6. The results of path analysis on the biopsychosocial factors affecting to functional disability and depression in osteoarthritis patients

\begin{tabular}{|c|c|c|c|c|c|c|}
\hline $\begin{array}{c}\text { Dependent } \\
\text { Variable }\end{array}$ & & $\begin{array}{c}\text { Independent } \\
\text { Variable }\end{array}$ & $\mathbf{b}^{*}$ & $\mathbf{S E}$ & $\mathbf{p}$ & $\boldsymbol{\beta}^{* *}$ \\
\hline \multicolumn{7}{|l|}{ Direct effect } \\
\hline Functional disability & $\leftarrow$ & Sex & $3 \cdot 36$ & 1.21 & 0.006 & 0.16 \\
\hline Functional disability & $\leftarrow$ & Age & 0.14 & 0.06 & 0.016 & 0.14 \\
\hline Functional disability & $\leftarrow$ & BMI & 0.31 & 0.17 & 0.070 & 0.11 \\
\hline Functional disability & $\leftarrow$ & History of injury & 2.27 & 1.16 & 0.051 & 0.12 \\
\hline Functional disability & $\leftarrow$ & Grade of $\mathrm{OA}$ & 1.32 & 0.65 & 0.041 & 0.12 \\
\hline Functional disability & $\leftarrow$ & Pain level & 0.41 & 0.12 & $<0.001$ & 0.22 \\
\hline Functional disability & $\leftarrow$ & Family support & -0.16 & 0.04 & $<0.001$ & -0.23 \\
\hline Functional disability & $\leftarrow$ & Peer support & -0.29 & 0.08 & $<0.001$ & -0.21 \\
\hline Depression & $\leftarrow$ & BMI & 0.23 & 0.10 & 0.021 & 0.14 \\
\hline Depression & $\leftarrow$ & Pain level & 0.16 & 0.07 & 0.022 & 0.15 \\
\hline Depression & $\leftarrow$ & Duration (year) & 0.27 & 0.12 & 0.025 & 0.13 \\
\hline Depression & $\leftarrow$ & Functional disability & 0.19 & 0.04 & $<0.001$ & 0.33 \\
\hline Depression & $\leftarrow$ & Family support & -0.05 & 0.03 & 0.042 & -0.13 \\
\hline Depression & $\leftarrow$ & Peer support & -0.09 & 0.05 & 0.045 & -0.12 \\
\hline \multicolumn{7}{|l|}{ Indirect effect } \\
\hline Pain level & $\leftarrow$ & BMI & 0.24 & 0.10 & 0.018 & 0.15 \\
\hline Pain level & $\leftarrow$ & History of injury & 2.19 & 0.68 & 0.001 & 0.21 \\
\hline Pain level & $\leftarrow$ & Grade of OA & 0.99 & 0.37 & 0.008 & 0.17 \\
\hline Pain level & $\leftarrow$ & Family support & -0.05 & 0.03 & 0.031 & -0.14 \\
\hline $\begin{array}{l}\text { Pain level } \\
\text { N observation }\end{array}$ & $\leftarrow$ & Peer support & -0.15 & 0.05 & 0.001 & -0.20 \\
\hline \multicolumn{7}{|l|}{ Fit model } \\
\hline $\mathrm{CMIN}=10.16$ & & $=0.97$ & & & & \\
\hline$=0.254$ & \multicolumn{2}{|r|}{$=0.99$} & & & & \\
\hline$=0.99$ & \multicolumn{2}{|c|}{ RMSEA $=0.04$} & & & & \\
\hline \multicolumn{7}{|c|}{${ }^{*} \mathrm{~b}=$ unstandardized path analysis coefficient } \\
\hline${ }^{* *} \beta=$ standardized pat & & ysis coefficient & & & & \\
\hline
\end{tabular}

2) Factors directly affecting to functional disability.

a) Sex was positively affected to functional disability. Female had higher risk on functional disability in OA patient $(\mathrm{b}=$ $3.36 ; \mathrm{SE}=1.21 ; \mathrm{p}=0.006)$.

b) Age was positively affected to functional disability. Older age increased the risk of functional disability in OA patient $(\mathrm{b}=$ $0.14 ; \mathrm{SE}=0.01 ; \mathrm{p}=0.016$ ). f) Peer support was negatively affected to depression in OA patient. Strong peer support decreased depression $(b=-0.09$; $\mathrm{SE}=0.05 ; \mathrm{p}=0.001$ ) c) BMI was positively affected to functional disability. Higher BMI increased functional disability $(b=0.31 ; \mathrm{SE}=0.17 ; \mathrm{p}=$ 0.070).

d) History of injury was positively affected to functional disability. OA patient who had experienced injury increased functional disability $(b=2.27 ; \mathrm{SE}=1.16 ; \mathrm{p}=$ 0.051).

e) Grade of OA was positively affected to functional disability. Higher grade of OA 
increased functional disability $(\mathrm{b}=1.32$; $\mathrm{SE}=0.65 ; \mathrm{p}=0.041$.

f) Pain level was positively affected to functional disability. Higher pain level increased functional disability $(b=0.41$; $\mathrm{SE}=0.12 ; \mathrm{p}<0.001$.

g) Family support was negatively affected to functional disability. Strong family support decreased functional disability $(\mathrm{b}=-0.16 ; \mathrm{SE}=0.04 ; \mathrm{p}<0.001)$.

h) Peer support was negatively affected to functional disability. Strong peer support decreased functional disability $(b=-$ $0.29 ; \mathrm{SE}=0.08 ; \mathrm{p}<0.001$ ).

3) Pain level was affected by BMI, history of injury, grade of OA, family support, and per support.

a) Pain level was positively affected by BMI. Pain level increased with higher BMI $(b=$ $0.24 ; \mathrm{SE}=-0.10 ; \mathrm{p}=0.018$ ).

b) Pain level was positively affected by history of injury. Had experienced injury was increased pain level $(b=2.19 ; \mathrm{SE}=$ $0.68 ; \mathrm{p}=0.001$ ).

c) Grade of $\mathrm{OA}$ increased pain level ( $b=$ 0.99; $\mathrm{SE}=0.37 ; \mathrm{p}=0.008$ ).

d) Pain level was negatively affected by family support. Higher family support decreased pain level $(b=-0.05 ; \mathrm{SE}=$ 0.03; $\mathrm{p}=0.031$ ).

e) Pain levels negatively affected by peer support. Higher peer support decreased pain level $(b=-0.15 ; \mathrm{SE}=0.05 ; \mathrm{p}=$ o.001).

\section{CONCLUSION}

\section{The effect of BMI on depression in} OA patient

The result of this study indicated that BMI had a positive effect on depression in OA patient. This finding is consistent with Rosemann et al. (2008) and Shimura et al., (2014). The relationship between obesity and depression had been widely studied. The previous study showed that obesity can predict future depression (Herva et al., 2006). Rosemann et al. (2008) stated that OA patient with obesity increased the risk of depression as measured by the PHQ-9 score. Physical limitation (especially the lower body), pain, and social contact limitations were considered to be clinical predictors of depressive disorder in $\mathrm{OA}$ patient. Several studies also support the finding that metabolic factors in OA patient with higher body weight increased the risk of depression (McIntyre et al., 2009).

BMI is associated with joint pain and joint function. Obesity is a risk factor for the development of knee OA (Jarvholm et al., 2005; Yoshimura et al., 2004; Mounach et al., 2007). Weight gain contributes to the growth of $\mathrm{OA}$ in the presence of increased load burden on joints through the mechanism of metabolic effect (Jarvholm et al., 2005; Kulcu et al., 2010). The excessive physical load can cause cartilage prone to fragmented and facilitated the development of OA. At the same time, the biomechanism of the joint is affected by the increase in the excess load and the influence of large quadriceps muscle work (Kulcu et al., 2010).

\section{The effect of pain level on depress- ion in OA patient}

This study indicated that the pain level had a positive effect on depression in $\mathrm{OA}$ patient. Depression is one of the major complications in the patient with an inflammatory disease, including OA (Shimura et al., 2014).

In addition, anti-depressant drug such as duloxetine can noble the pain in OA patient. This finding suggests that central nervous system mechanisms can link pain and depression in OA (Abou-Raya et al., 2012; Sharma et al., 2016). 


\section{The effect of duration on depress- ion in OA patient}

The result of this study indicated that the duration of pain had a positive effect on depression in OA patient. This finding is consistent with Cubukcu et al. (2012) which stated that age and duration of OA pain were positively associated with grade of OA, functional disability, and depression.

\section{The effect of functional disability on depression in OA patient}

This study showed that functional disability had a positive effect on depression in OA patient. Mesci et al. (2015) stated that elderly people with more physically active had better quality life and lower depression than elderly patients with less activity.

Mallen et al. (2007) and Dekker et al. (2009) reported that anxiety was one of the predictor factors for decreased physical function in OA patient who had suffered from knee OA for 18 months. This study is consistent with Dunlop et al. (2005) who reported that depression was associated with the pain and physical limitations of OA patients who had OA for 2 years.

OA patient often experiences depression, lower physical activity levels, and lower quality of life (Rosemann et al., 2008). Kucuksen et al. (2014) reported that more than $49.3 \%$ of knee OA patients were depressed.

The impact of psychological factors on the functional decline was seen from patients who avoid daily physical activity (Steultjens et al., 2002). OA patient tent to reduce physical activity because of joint pain arising from movement. The negative effect of anxiety and depression were thought to increase the tendency to avoid physical activity. However, low activity level caused muscle weakness, joint instability, and increased functional disability (Dekker, 2009).

\section{The effect of family support on depression in OA patient}

The result of this study indicated that family support had a negative effect on depression in OA patient. This finding is consistent with Hung et al. (2016) which stated that family support reduces symptoms of depression in OA patients.

\section{The effect of peer support on depression in OA patient}

The result of this study indicated that peer support had a negative effect on depression in OA patient. This study is consistent with Park and Unutzer (2011) which stated that peer support plays an important role in decreasing depressive symptoms in $\mathrm{OA}$ patient.

\section{The effect of sex on functional} disability in OA patient

The result of this study indicated that female has a positive effect on functional disability in OA patient. This finding is consistent with Theis et al. (2007) that women with osteoarthritis experienced lower physical function, more severe pain, more depression, and had higher activity limitation than men.

Musumeci et al. (2015) reported that hormonal factors and differences in bone and ligament structures between female and male can influence the development of osteoarthritis. OA incidence in women increased over 50 years is thought to be due to estrogen levels after menopause. Chondrocytes have functional estrogen receptors, these cells are affected by estrogen (Bijlsma et al., 2011).

\section{The effect of age on functional disability in OA patient}

The result of this study indicated that age had a positive effect on functional disability in OA patient. Degeneration of cartilage and inflammation around the joint that occurred in the elderly causes pain, joint 
Journal of Epidemiology and Public Health (2018), 3(2): 292-306

https://doi.org/10.26911/jepublichealth.2018.03.02.08

stiffness, swelling, and disability (Ciombor et al., 2003; Woo et al., 2004).

\section{The effect of BMI on functional disability in OA patient}

The result of this study indicated that BMI has a positive effect on functional disability in OA patient. This finding is consistent with Dekker et al. (2009); Holla et al., (2014); and Külcü et al., (2010) that BMI was positively associated with pain and physical activity limitation in the patient with knee OA joint.

Rosemann et al. (2008) and Zoico (2004) reported that obese OA patients tend to have more physical functional limitations than those with normoweigth. This finding can be caused by two reasons. First, the perception of pain causes the patient to feel limited activity. Secondly, muscle strength, particularly the femoral quadriceps musculus shows an important role in knee joint stability and increased OA symptom.

\section{The effect of history of injury on functional disability in OA patient} The results of this study indicated that OA patient who had experienced injury decreased functional disability. This finding is consistent with Lau et al., (2000) that the history of injury was associated with hip OA in both male and female.

11. The effect of grade of $\mathrm{OA}$ on functional disability in OA patient The result of this study indicated that grade of OA had a positive effect on the functional disability in OA patient. This finding is consistent with Rydevik et al. (2010) that moderate and severe hip and pelvic OA patient had an effect on knee joint strength and decreased the ability of physical activity. Kocak et al. (2009) also stated that the strength of the femoral quadriceps muscle decreased with the higher grade of OA.
12. The effect of pain level on functional disability in OA patient

This study indicated that pain positively effected on functional disability in $\mathrm{OA}$ patient. Pain caused by osteoarthritis reduced ability to perform daily activities and decreased quality of life of OA patient (Grotle et al., 2008; Boutron et al., 2008).

Pain due to osteoarthritis is thought to be caused by a complex process of the central nervous system and peripheral nervous system (peripherals) (Dieppe et al., 2005; Hunter et al., 2008; Clauw and Witter, 2009; Murphy et al., 2011).

Pain and limitation of physical function such as walking, standing, sitting, and climbing stairs are the main symptoms of knee and hip joint osteoarthritis. The result of previous studies showed that decreased muscle strength is the cause of limited physical function, especially in knee joint OA. Muscle weakness and knee joint instability affect the limitations of physical function. Knee joint instability (eg, to maintain position or control movement with different load), muscle and joint weakness, and poor varus-valgus movement contribute greatly to activity limitation (Felson et al., 2007; Alkan et al., 2014; van der Esch et al., 2007).

\section{The effect of family support on} functional disability in OA patient This study showed that strong family support decreased functional disability in OA patient. This finding is consistent with Ilori et al. (2016) strong family support can improve the quality of body function to perform daily activities.

The limitation of physical function due to pain also affects social relationship with family member and peer. Family members often have to assist patient to perform their daily activities, monitor drug consumption and therapeutic control, and 
engage in decision-making when consulting doctor (da Cruz Dde et al., 2004).

\section{The effect of peer support on} functional disability in OA patient

This study indicated that peer support can reduce functional disability in OA patient. Good mental health, good self efficacy, and strong social support including from peers were a protective factor against decreased physical function in patients with OA knee joints (Dekker et al., 2009).

\section{REFERENCE}

Abou-Raya S, Abou-Raya A, Helmii M (2012). Duloxetine for the management of pain in older adults with knee osteoarthritis: randomised placebo controlled trial. Age Ageing. 41(5): 646-652.

Alkan BM, Fidan F, Tosun A, Ardıçoğlu O (2014). Quality of life and selfreported disability in patients with knee osteoarthritis. Modern Rheumatology, 24(1): 166-171.

Bijlsma JW, Berenbaum F, Lafeber FP (2011). Osteoarthritis: an update with relevance for clinical practice. Lancet. 377(9783): 2115-26.

Blagojevic M, Jinks C, Jeffery A, Jordan KP (2010). Risk factors for onset of osteoarthritis of the knee in older adults: a systematic review and metaanalysis. Osteoarthritis and cartilage, 18:24-33.

Boutron I, Rannou F, Jardinaud-Lopez M, Meric G, Revel M, Poiraudeau S (2008). Disability and quality of life of patients with knee or hip osteoarthritis in the primary care setting and factors associated with general practitioners' indication for prosthetic replacement within 1 year. Osteoarthritis Cartilage. 16(9):1024-1031.

Ciombor DM, Aaron RK, Wang S, et al (2003). Modification of osteoarthritis by pulsed electromagnetic field-a morphological study. Osteoarthr Cartil.11: 455-62.

Clauw D, Witter J (2009). Pain and rheumatology: thinking outside the joint. Arthritis Rheum. 60(2): 321-324.

Cubukcu D, Sarsan A, Alkan H (2012). Relationship between pain, function and radiographic findings in osteoarthritis of the knee: a cross-sectional study. Arthritis. 1-5.

da Cruz Dde A, Pimenta CA, Kurita GP, de Oliveira AC (2004). Caregivers of patients with chronic pain: responses to care. Int J Nurs Terminol Classif. 15(1): 5-14.

Dekker J, Dijk GM, Veenhof C (2009). Risk factors for functional decline in osteoarthritis of the hip or knee. Current Opinion in Rheumatology. 21: 520524.

Dieppe PA, Lohmander LS (2005). Pathogenesis and management of pain in osteoarthritis. Lancet, 365(9463): 965-973.

Dunlop DD, Semanik P, Song J, et al. (2005). Risk factors for functional decline in older adults with arthritis. Arthritis Rheum. 52:1274-1282.

Felson DT, Niu J, McClennan C, et al. (2007). Knee buckling: prevalence, risk factors, and associated limitations in function. Ann Intern Med. 147:534-540.

Grotle M, Hagen KB, Natvig B, et al (2008). Obesity and osteoarthritis in knee, hip and/or hand: An epidemiological stu$\mathrm{dy}$ in the general population with 10 years follow-up. BMC Musculoskeletal disorders. 9: 132.

Haq I, Murphy E, Dacre J (2003). Osteoarthritis. Postgrad Med J, 79: 377383.

Herva A, Laitinen J, Miettunen J, Veijola J, Karvonen JT, Laksy K, Joukamaa M 
Journal of Epidemiology and Public Health (2018), 3(2): 292-306

https://doi.org/10.26911/jepublichealth.2018.03.02.08

(2006). Obesity and depression: results from the longitudinal Northern Finland 1966 Birth Cohort Study. Int J Obes (Lond). 30: 520-527.

Holla J, Roorda LD, Leeden M, Dekker J (2014). FRIo408 Body mass index and depression are independently associated with knee pain and activity limitations in knee osteoarthritis: Results from the AMS-OA cohort. Annals of the Rheumatic Diseases. 71(3): 452-452.

Hootman JM, Helmick CG (2006). Projections of US prevalence of arthritis and associated activity limitations. Arthritis Rheum. 54: 226-229.

Hung M, Bounsanga J, Voss MW, Crum AB, Chen W, dan Birmingham WC (2016). The relationship between family support; pain and depression in elderly with arthritis. Journal Psychology, Health \& Medicine. 22(1): 75-86.

Hunter D, McDougall J, Keefe F (2008). The symptoms of osteoarthritis and the genesis of pain. Rheum Dis Clin North Am. 34(3):623-643.

Ilori T, Ladipo MM, Ogunbode AM, Abimbola M (2016). Knee osteoarthritis and perceived social support amongst patients in a family medicine clinic Knee osteoarthritis and perceived social support amongst patients in a family medicine clinic. South African Family Practice, 58(6): 202206.

Jarvholm B, Lewold S, Malchau H, Vingard E (2005). Age, bodyweight, smoking habits and the risk of severe osteoarthritis in the hip and knee in men. Eur J Epidemiol. 20: 537-42.

Keefe FJ, Buffington ALH, Studts JL, Smith SJ, Gibson J, Caldwell DS (2002). Recent Advances and Future Directions in the Biopsychosocial Assess- ment and Treatment of Arthritis. Journal of Consulting and Clinical Psychology, 70(3): 640-655.

Kocak FU, Unver B, Karatosun V, Bakirhan $S$ (2009). Associations between Radiographoc Changes and Function, Pain, Range of Motion, Muscle Strenght and Knee Function Score in Patients with Osteoarthritis of the Knee. J. Phys. Ther. Sci. 21: 93-97.

Kucuksen S, Yllmaz H, Karahan AY, Bagcaci S (2014). The prevalence of depression and its relevance to clinical and radiological characteristics among older adults with knee osteoarthritis. Clinical Medicine Research. 3(2): 25-30.

Kulcu DG, Yanik B, Atalar H, Gülsen G (2010). Associated Factors with Pain and Disability in Patients With Knee Osteoarthritis. Turk J Rheumatol. 25: 77-81.

Lau EC, Cooper C, Lam D, Chan VN, Tsang KK, Sham A (2000). Factors associated with osteoarthritis of the hip and knee in Hong Kong Chinese: obesity, joint injury, and occupational activities. Am J Epidemiol, 152(9): 855-862.

Laupattarakasem W, Laopaiboon, Laupattarakasem P, Sumananont C (2008). Arthroscopic debridement for knee osteoarthritis. Cochrane Database Syst Rev. 23(1): CDoo5118.

Mallen CD, Peat G, Thomas E, et al (2007). Predicting poor functional outcome in community-dwelling older adults with knee pain: prognostic value of generic indicators. Ann Rheum Dis. 66: 14561461.

McIntyre RS, Rasgon NL, Kemp DE, Nguyen HT, Law CWY, Hon, Taylor $\mathrm{VH}$, et al. (2009). Metabolic Syndrome and Major Depressive Disorder: Co-occurrence and Pathophy- 
siologic Overlap. Current Diabetes Reports. 9: 51-59.

Mesci E, Icagasioglu A, Mesci N, Turgut ST (2015). Relation of physical activity level with quality of life, sleep and depression in patients with knee osteoarthritis. North Clin Istanbul. 2(3):215-221.

Mounach A, Nouijai A, Ghozlani I, Ghazi M, Achemlal L, Bezza A, et al (2007). Risk factors for knee osteoarthritis in Morocco. A case control study. Clin Rheumatol. 3: 323-6.

Murphy SL, Lyden AK, Phillips K, Clauw DJ, Williams DA (2011). The Association between Pain, Radiographic Severity, and Centrally-mediated Symptoms in Women with Knee Osteoarthritis. Arthritis Care Res (Hoboken). 63(11): 1543-1549.

Musumeci G, Szychlinska MA, Mobasheri A (2015). Age-related degeneration of articular cartilage in the pathogenesis of osteoarthritis: Molecular markers of senescent chondrocytes. Histol. Histopathol. 30: 1-12.

Park M, Unutzer J (2011). Geriatric Depression in Primary Care. Psychiatr Clin North Am. 34(2): 469-x.

Pooye S, Barbara B (2010). Cultural Factors Leading to Overweight and Obesity: Cross-Cultural Analysis of Japan and The United States of America. Bachelor Thesis Marketing 2009-2010. ANR: 256491. Universiteit Van Tilburg.

Rydevik K, Fernandes L, Nordsletten L, Risberg MA (2010). Functioning and Disability in Patients With Hip Osteoarthritis With Mild to Moderate Pain. Journal of Orthopaedic \& Sports Physical Therapy, 40(10): 617-624.

Rosemann T, Grol R, Herman K, Wensing M, Szecsenyi J (2008). Association between obesity, quality of life, phy- sical activity and health service utilization in primary care patients with osteoarthritis. Int J Behav Nutr Phys Act. 5:4.

Sharma A, Kudesia P, Shi Q, Gandhi R (2016). Anxiety and depression in patients with osteoarthritis: impact and management challenges. Rheumatology: Research and Reviews. 8: 103-113.

Shimura Y, Kurosawa H, Tsuchiya M, Kaneko H, Liu L, Sadatsuki R, Yusup A, et al. (2014). Association between synovitis and depression in patients with knee osteoarthritis: a crosssectional study. Osteoarthritis and Cartilage 22: S57-S489.

Steultjens MP, Dekker J, Bijlsma JW (2002). Avoidance of activity and disability in patients with osteoarthritis of the knee: the mediating role of muscle strength. Arthritis Rheum. 46: 1784-1788.

Theis K, Helmick C, Hootman J (2007). Arthritis burden and impact are greater among U.S. women than men: intervention opportunities. J Womens Health. 16(4): 441-453.

van der Esch M, Steultjens M, Harlaar J, et al. (2007). Joint proprioception, muscle strength, and functional ability in patients with osteoarthritis of the knee. Arthritis Rheum. 57:787-793.

Vos T, Flaxman AD, Naghavi M, Lozano R, Michaud C, Ezzati M, et al (2012). Years lived with disability (YLDs) for 1160 sequelae of 289 diseases and injuries 1990e2010: a systematic analysis for the Global Burden of Disease Study 2010. Lancet, 380(9859): 2163e96.

Woo J, Lau E, Lee P, et al (2004). Impact of osteoarthritis on quality of life in a Hong Kong Chinese population. J Rheumatol. 31: 2433-8. 
Journal of Epidemiology and Public Health (2018), 3(2): 292-306

https://doi.org/10.26911/jepublichealth.2018.03.02.08

Yoshimura N, Nishioka S, Kinoshita $\mathrm{H}$, Hori N, Nishioka T, Ryujin M, et al (2004). Risk factors for knee osteoarthritis in Japanese women: heavy weight, previous joint injuries, and occupational activities. J Rheumatol. 31: $157-62$.
Zoico E, Di FV, Guralnik JM, Mazzali G, Bortolani A, Guariento S, Sergi G, et al. (2004). Physical disability and muscular strength in relation to obesity and different body composition indexes in a sample of healthy elderly women. Int $\mathrm{J}$ Obes Relat Metab Disord. 28: 234-241. 